\title{
The Pragmatic Functions and the Translatability of "Ťayib" in Jordanian Spoken Arabic
}

\author{
Ahmad Mohammad Ahmad Al-Harahsheh, Mahmoud Kanakri \\ Yarmouk University, Irbid, Jordan
}

\begin{abstract}
Discourse markers are functional and meaningful in discourse, as they orient the interlocutors to comprehend the meaning communicated in discourse as a whole. This study aims at studying the pragmatic functions of the Arabic term Tayyib and its cognate Tabb and its translatability in JSA (Jordanian Spoken Arabic). The data analyzed consisted of 18-videotaped dyadic conversations, each conversation lasted for 30 minutes. Discourse analysis, conversation analysis, and relevance theory were employed as a theoretical framework for this study. The study concludes that the discourse marker tayyib and its cognate $t a b b$ are functional, and convey ten pragmatic functions in JSA.
\end{abstract}

Keywords: discourse markers, Jordanian Arabic, discourse analysis, translation, relevance theory

\section{Introduction}

Discourse analysis focuses on the analysis of language in use, and it studies not only the description of linguistic forms but also the purposes and functions of them (Brown \&Yule, 1983). Apparently, discourse can be understood at the pragmatic level, since the main purpose of language is to exchange meanings among the speech community members. This paper aims to shed light on one of the discourse markers in JSA (Jordanian Spoken Arabic), the word tayyib ("Okay", "fine", lit. "good"). It is frequently utilized in JSA. It is employed as a word of agreement, a continuer and an affirmation. Discourse markers can be defined as "a class of expressions, each of which signals how the speaker intends the basic message that follows to relate to the prior discourse" (Fraser, 1990, p. 387). In other words, discourse markers are used to mark the boundaries of topics in discourse, i.e., the ending of one topic and the start of the next one. They also have a significant role in controlling the pragmatic nature of a discourse (Schiffirn, 1987). According to Fraser (1990), the meaning of a sentence is analyzable into two distinguished types of information: First, content that means every sentence conveys a single message. Secondly, pragmatic meaning which refers to the speaker's intention "illocutionary meaning". Suffice it to say, discourse markers are functional in discourse as they organize the conversation, i.e., they can be utilized as signals to the discourse boundaries such as the beginning and the ending of an utterance.

One discourse marker in Arabic is the word tayyib and its cognate tabb. Following Aijmar (1996), it will be viewed as a local marker, i.e., it occurs within a certain topic, and global marker as well, i.e., to signpost transition from one topic to another. This paper aims to investigate the pragmatic functions of tayyib as well as to answer the following questions: (1) What are the pragmatic functions of tayyib ("Okay") in JSA?; (2) Is there a gender differences in the use of tayyib in JSA?; and (3) How can be tayyib translated in JSA?

Ahmad Mohammad Ahmad Al-Harahsheh, assistant professor, Translation Department, Yarmouk University. Mahmoud Kanakri, professor, Translation Department, Yarmouk University. 
This study is original and significant, because we have not found a single paper that tackles this linguistic phenomenon in JSA.

\section{Background}

It is not uncommon that all linguistic units cooperate with each other to facilitate the understanding of the meaning of discourse. As linguists, we should not degrade any linguistic element as these elements together lead us to understand the whole message that interlocutors wish to communicate. Clark (1996) explained that there are four main pieces of evidence that participant in talk-in-interaction can understand what has been communicated: First, the use of presupposition of understanding occurs when interlocutors suitably respond to each other. Second, assertions of understanding takes place when the interlocutors produce backchannels such as huh, ah... etc.. Third, displays of understanding, i.e., answers to questions that display how the question was interpreted. Finally, exemplification, i.e., the repetition and paraphrasing also let interlocutors check for an acceptable understanding. Hockey (1993) stated that discourse markers, as termed by Schiffrin (1987), do not contribute to the meaning of discourse. However, they are related to the structure of discourse. It is observed that the interlocutors tend to produce backchannels, short responses usually of acknowledgement. The purpose behind these responses is to give each other the feeling that they understand what has been communicated to maintain the main stream of communication.

Beach (1993, p. 327) indicated that the participants in a conversation tend to use Okay in order to "organize conversational activities". That is to say, they aim to design the previous turn in order to be responsive as well as to shape the next turn. WANG, Tsai, Goodman and MENG (2010) found that Okay in Taiwan Mandarin is used to show acceptance or agreement with the other speaker's move or act. In this sense, Okay occurs at the beginning of the turn. In addition, it can be used as a signal to the other participant that the current speaker wishes to finish the current topic and he/she wants to start a new one. Furthermore, when Okay is employed alone, it terminates the topic, and it expresses the speaker's acknowledgement to what the other interlocutor has been said. However, when it is employed within a turn, it finishes the topic. Overall, Okay can be employed to mark boundary exchanges; to signal the relatedness of the current utterance to the previous one, and to show whether the turn is still available (WANG et al., 2010). Schegloff and Sacks (1973) also explained that Okay is used as a pre-closing statement to close the conversation.

Backchannels include "uh huh", "yeah", and "mmm", request for clarification, brief restatement of something just said by another, head nodes and shakes. Schegloff (1982) explained two uses for backchannels: First, they are evidence on the attention, interest and understanding on the listener's part. The second function is to keep the conversation going smoothly. "Uh huh", "yeah"... etc., could be a claim that the listener is interested in what is saying or he understands what the other is being talking (Schegloff, 1982). It is apparent that this can be determined from the body movement and facial expressions. Therefore, it is difficult to know whether the listener is interested or he/she understands what is being said, or he/she just claims that he/she understands to keep the track of the conversation going on. The same is true for the word tayyib ("Okay", "right") in Jordanian Arabic. It has been employed as a backchannel in order to mark understanding of what has been said in the prior turn. In addition, it has been used regularly at the beginning of the turn as an acknowledgment of what has been said and then it is followed by a question, especially when the listener does introduce first and then he/she asks. 


\section{Theoretical Frameworks}

The theoretical framework of the current study draws on a multi-faceted approach such as discourse analysis, conversation analysis and relevance theory of Sperber and Wilson's $(1986,1995)$. This theory deals with spoken discourse, especially a conversation as a process. Put it differently, the interlocutors in a conversation attempt to make their utterances relevant to what they intend. The listener searches for the meaning in any given situation, as he/she looks for the meaning that is suitable for context. Sperber and Wilson $(1985,1995)$ stated that there are two ways to understand the communicated meaning between the interlocutors: first, the speaker encodes his or her thought, and he/she transmits it to the listener. The second way is that both interlocutors make sure that they transmitted as much information as needed in a particular context. In this sense, the context plays a pivotal role in understanding the message that each participants aims to convey in conversation.

\section{Participants}

The participants of the study were 36 speakers of Jordanian Arabic. They were University students. The data analyzed consisted of 18 Jordanian Arabic dyadic and spontaneous conversations, which were conducted in January 2010 at Yarmouk University (Irbid, Jordan).Their ages were between 18-26. 145 occurrences of tayyib and its cognate $t a b b$ were found in these conversations, 51 for tayyib and 94 for $t a b b$. The length of each conversation was 30 minutes, 9 hours of videotaped conversations, about 95,000 words.

\section{Methodology}

The methodology of this study is a mixed approach. However, it is quantitative in nature; we rely on our observations and experiences as Jordanian linguists. The participants were met in a staff room on the campus of Yarmouk University. The room was showed to them to reduce their uneasiness in a strange environment. Then, they were asked about the suitability of the room to make sure that they were in a comfortable environment. After they were seated in two padded chairs, in front of each, they were asked to talk about any topic they wished in order to have a spontaneous conversation.

The stationary video camera was positioned about three meters away from the participants. The participants were asked to talk with each other for 30 minutes; the researcher left the room during the conversation to avoid any influence on the main stream of communication. Thirty minutes later, the researcher came back to switch off the recording devices.

The data used in the study comprised 18 dyadic and spontaneous conversations in Jordanian Arabic. Basic quantitative measures were used such as the frequencies of the tayyib and its cognate $t a b b$, since this procedure was suitable for fulfilling the aim of the study.Then, discourse analysis approach was employed as a theoretical framework.

\section{Data Analysis and Discussion}

One intriguing and vital inquiry in the field of linguistics and discourse analysis is the conundrum of how people communicate and understand each other. Unfortunately, linguistics has little to offer in this regard. However, it is field of discourse analysis which has to a large extent succeeded in handling this inquiry by that the process of understanding can be achieved through claiming and proving. Wilson (1994) talked about covert and overt communication. Wilson maintained that it is the intension of the participants of a 
conversation that counts. The present research will offer more evidence and support to the framework proposed by Wilson.

The term tayyib is an Arabic term which literally means "Okay, fine Lit. good". Tayyib takes two forms, tayyib and its cognate form $t a b b$. The former occurs fifty-one times and the latter occurs ninety four times. In our corpus, tayyib serves two primary functions, one is agreement and the other is disagreement. In the former function it occurred one hundred and twenty-one times, while in the latter it occurred three times only.

Structurally, tayyib occurred in the following structures:

(a) Before questions, as in Example 1:

Example (1) Tayyib ? almushikileh halla? Bil-shuighil wa-ll-innu ma mitwaffir

Ok the-problem now in-work or-that no available

"Ok, is the problem now in work or is it not available?"

(b) Before a negative statement (see Example 2):

Example (2) "Tayyib, ?ihna lissa ma wsilna Cala shaan yihkuuna......."

Ok, we not yet not arrive so-that the reason they-tell-us

"Ok, we have not yet arrived to let them tell us that

(c) Tayyib followed by an affirmative statement (see Example 3):

Example (3) "Tayyib xallina bi-?iClam ............"

"Ok, let-us in-the media..........."

"Ok, let us discuss (something) in the media...."

(d) Before an NP as the following examples show (see Example 4):

Example (4) Tabb Mohammad Al-shorman

Ok, Mohammad Al-shorman

"Ok, what do you think/what about Mohammad Al-shorman?"

(e) Can occur alone as a response to a statement, as in Examples 5a-5b:

Example (5a) B itkun-1-muhadhara ?issaCa eamanyih

Was-the-lecture o'clock eight

"The lecture was at eight o'clock"

Example (5b) Tayyib

After scrutinizing our corpus, we found that the term tayyib and its cognate form $t a b b$ serve the following functions. First, they are employed as a marker of backchannel with what precedes them, especially when they occur initially in discourse, as the Examples 6-7 show next:

Example (6) Tayyib shu Cashan-1-bahe

Ok, what about-the-research paper?

"Ok, what about the research paper?"

Example (7) Tayyib, w-inti shu biCimali hal-?ayyam?

"Ok, and-you what do these-days"

"Ok, and you, what do you do these days"

This function fosters what WANG et al. (2010) arrived at regarding "ok" when they found that this term occurs sentence initial to indicate acceptance or agreement.

The second pragmatic function of tayyib and its cognate is that they are used as a marker to mean "stop, let us understand the matter", as in Example 8. 
Example (8) Tayyib, ?il-mushkila halla? Bi-shshughul walla ?innu ma mitwaffir

Ok the-problem now in-the-work or that not available

"Ok, is the problem in work or that it is not available?"

This speaker signals his or her misunderstanding by the use of tayyib here to mean: "Let us stop to find out what the problem is." This sort of function appears when there is a discussion of a certain issue and the hearer could not figure out what the real situation is. The use of tayyib signals a need from the hearer side to understand the issue at hand.

The third pragmatic function of tayyib and its cognate is to show a break of a certain discourse to show objection to what has been said so far. The following Example 9 illustrates this point:

Example (9) Tayyib balki innu-ttanyeh Casheh Cisheh ?illi hi btihlam fiiha?

Ok, suppose that - the second live living which she dreamt of

"Ok, suppose that the second lived the sort of life that she dreamt of ?"

Following Reisigl and Wodak (2001), we like to call this type of discourse break a "discoursal strategy". The last term can be defined as "accurate and intentional plans practices adopted to achieve a particular social, psychological or linguistic aim” (Baker \& Ellege, 2011, p. 38).

Naturally, participants in a certain conversation or talk do not always accept what others say, especially in the case of men rather than women (Holmes, 1992).

The fourth pragmatic function of the terms at hand is an introduction of a new topic. When participants of a certain topic feel they have said enough about a certain topic, they usually shift into a new one. The marker of this shift is the term tayyib and its cognate tabb. Consider the following Example 10:

Example (10) Tabb ?assu?al ?ie日ani?

Ok, the-question the-third

"Ok, the second question?"

This example refers to a situation where speakers finished discussing the first question and there was a need to shift into the second question. This shift is introduced by the word tabb.

The fifth pragmatic function is that it is used as mitigating term or softener for the disagreement force, as the following Example 11 shows:

Example (11) Tabb xallina-nkun fair in $\wedge$, ok?

Ok, let-us be fair enough, ok?

"Ok, let us be fair enough?"

The producer of this utterance does not want to be blatant to say "No". Instead, he used tabb and followed this word by "let us be fair enough". This discoursal strategy can be subsumed under polite strategies that speakers resort to when they do not want to seem rude or impolite.

The sixth pragmatic function of the terms at hand is a marker of challenge or confrontation. The following utterances illustrate this point (see Examples 12a-12b):

Example (12a) Tabb xu yaCni biddak?

Example (12b) Tabb, xu yacni?

In Example 12a, the speaker sends an indirect message to the addressee that tabb "Ok, I have understood your point, what do you want now? Do you want to fight?". However, in Example 12b the speaker does not necessarily indicate an indirect challenge; he may be enquiring about the whole matter or problem. Sometimes tone plays an important role in explicating the real intention of the speaker. Producing Example $12 \mathrm{~b}$ in a 
sarcastic way could highly lead to a fight or quarrel.

The seventh pragmatic function of tayyib and its cognate $t a b b$ is that they signal the end of discourse, especially when it is accompanied with the expression "?inshalla" and "by Allah's will", as the following Example 13 shows:

Example (13) Tayyib, inshalla xeir, Allah ywaffgak

Ok, by-Allah's will good Allah help-you

"Ok, may Allah make is smooth. May Allah help you!"

The eighth pragmatic function of tayyib and its cognate is to send a message to the interlocutor to be patient. The following Example 14 illustrates this point:

Example (14) Tayyib, tayyib, raћ ?ajiik

Ok Ok will I-come

"Ok, ok, I will come to you."

The ninth pragmatic function of tayyib is "to give permission", as in the following Example 15:

Example (15) Tayyib, btigdar Hassa trouћ

Ok, you-can now go

"Ok, you can now go."

The tenth pragmatic function of the terms at hand is that they can be used as gap fillers. Speakers do not always have ready answers to what they hear or are asked. In this situation they use tayyib to fill this gap, as in the following Example 16:

Example (16) ?ana Tabb baCmal reir heik

I filler I-do not this

"I do it differently."

\section{Conclusions}

This study concludes that tayyib and its cognate $t a b b$ are functional in JSA, and they convey ten pragmatic meanings or functions, many of which are Arabic specific. That is, such meanings or functions are anchored on mutual knowledge of Arabic. Thus it is only Arabs or learners of Arabic who could comprehend such meanings. This piece of work also shows that every day talk is a rich source of data, and in particular, of terms and expressions, that are clearly imbued with cultural meanings. The term tayyib and many other similar Arabic terms mirror various Arabic cultural values. Similar to Stubbs (1983) and many other researchers, the writers of this study propose a systematic study of similar other cultural and linguistic terms. By such studies one can envisage a full-fledged picture of the Arabic culture with its various dimensions.

\section{References}

Aijmer, K. (1996).Conversational routines in English: Convention and creativity. London: Longman.

Baker, P., \& Ellege, S. (2011). Key terms in discourse analysis. New York: Continuum.

Beach, W. A. (1993). Transitional regularities for "casual” "Okay" usages. Journal of Pragmatics, 19, 325-352.

Brown, L., \& Yule, G. (1983). Discourse analysis. Cambridge: Cambridge University Press.

Clark, H. (1996). Using language. Cambridge: Cambridge University Press.

Fraser, B. (1990). An approach to discourse markers. Journal of Pragmatics, 14, 383-395.

Hockey, B. A. (1993). Prosody and the role of okay and uh-huh in discourse. Proc. ESCOL, 92, 128-136.

Holmes, H. (1992). An introduction to sociolinguistics. London: Longman.

Hopper, P., \& Thompson, S. (1984). The discourse of lexical categories in universal grammar. Language, 60, 703-752. 
Johnstone, B. (2008). Discourse analysis (2nd ed.). Oxford: Blackwell.

Jucker, A. H., \& Smith, S. W. (1998). And people just you know like "wow": Discourse makers as negotiating strategies. In A. H. Jucker \& Y. Zov (Eds.), Discourse markers: Description and theory (pp. 171-201). Amsterdam/Philadelphia: John Benjamins.

Reisigl, M., \& Wodak, R. (2001). Discourse and discrimination. London: Routledge.

Sacks, H. (1972). On the analyzability of stories by children. In J. J. Gumperz \& D. Hymes (Eds.), Directions in sociolinguistics: The ethnography of communication (pp. 325-345). New York: Holt, Rinehart and Winston.

Schegloff, E. (1982). Discourse as an interactional achievement: Some uses of uh huh and other things that come between sentences. In D. Tannen (Ed.), Analyzing discourse: Text and talk. Washington, D.C.: Georgetown University Press.

Schegloff, E. A., \& Sacks, H. (1973). Opening up closings. Semiotica, 1, 289-327.

Schiffrin, D. (1987). Discourse markers. Discourse studies (Vol. 12(2)). Cambridge: Cambridge University Press.

Sperber, D., \& Wilson, D. (1986, 1995). Relevance: Communication and cognition. Oxford: Blackwell.

Stubbs, M. (1983). Discourse analysis: The sociolinguistic analysis of natural language. Chicago: The University of Chicago Press.

WANG, Y. F., Tsai, P.-H., Goodman, D., \& MENG, Y. L. (2010). Agreement, acknowledgment, and alignment: The discourse-pragmatic functions of hao and dui in Taiwan Mandarin conversation. Discourse Studies, 12(2), 241-267.

Wilson, D. (1994). Relevance and understanding. In B. Gillian et al. (Eds.), Language and understanding. New York: Oxford University Press. 